\title{
ArTE CONTEMPORÂNEA E GEOMETRIAS?! REFLEXÓES SOBRE A PRÁTICA
}

\author{
Marcos Antonio Gonçalves Júnior
}

\section{RESUMO}

O presente trabalho apresenta uma reflexão sobre dois aspectos: primeiramente a possibilidade de realizar um trabalho interdisciplinar, em sala de aula, envolvendo a pintura contemporânea, especialmente o cubismo e o abstracionismo, e a matemática, especialmente a geometria. $\mathrm{O}$ autor busca um caminho coerente que lhe permita uma conexão com as artes, partindo dos contrastes entre a Geometria Euclidiana e a Geometria Fractal. Posteriormente, o autor faz uma reflexão sobre a sua própria prática profissional, relatando, brevemente, sua experiência em sala de aula com esse tema e (re)pensando as futuras ações como professor.

Palavras-Chave: Arte Contemporânea, Geometria Euclidiana, Geometria Fractal, reflexão sobre a prática, Educação Matemática.

\section{Contemporary art and geometries?! Reflection upon the teaching practice}

\section{Abstract}

This article presents a reflection on two aspects: firstly, on the possibility of developing an interdisciplinary work in classroom involving the contemporary picture - specially the cubism, abstractionism and Mathematics - mainly geometry. The author tries a coherent path that allows him to establish a connection through art, starting from the contrast between the Euclidean Geometry and the Fractal Geometry. Next, the author reflects on his professional practice reporting briefly his experience in classroom with this theme and about future actions as a teacher.

KEY wORDs: Contemporary Art, Euclidean Geometry, Fractal Geometry, Reflection on the teaching practice, Mathematics Education.

O objetivo deste texto é apresentar uma conexão entre os conceitos de dimensão física, regularidades e padrões (numéricos e geométricos) e a Pintura Cubista, e entre os conceitos de caos e aleatoriedade e a Pintura Abstrata. Essa concepção aconteceu durante os estudos que fiz para criar

\footnotetext{
* Professor de Matemática do Centro de Ensino e Pesquisa Aplicada à Educação da Universidade Federal de Goiás (Cepae/UFG). E-mail: margonjunior@yahoo.com.br.
} 
e planejar a disciplina intitulada Geometrias e Artes, lecionada aos alunos do Ensino Médio do Centro de Ensino e Pesquisa Aplicada à Educação da Universidade Federal de Goiás (Cepae/UFG) no ano de 2007. Inserindose dentro da grade de disciplinas optativas da área de Exatas do Cepae, a disciplina abordou os contrastes entre a Geometria Fractal e a Geometria Euclidiana, articulados a partir de algumas etapas da Arte Contemporânea.

Entre outros aspectos, considerando o 'caminho' teórico e a conexão concebida, determinantes para a criação da disciplina, e que integram a constituição do 'caminho didático', tenho também como objetivo fazer uma breve reflexão sobre essa experiência pedagógica.

Cabe ressaltar que não se trata do relato de uma pesquisa feita com os alunos ou com o professor tendo o ensino e aprendizagem como objeto. Trata-se, antes, de uma reflexão sobre as possibilidades de caminhos a seguir e práticas a abordar, tendo como perspectiva a idéia da interdisciplinaridade.

\section{Das Geometrias, das Artes e das possibilidades}

DEFINIÇÓES: I. Ponto é o que não tem partes, ou o que não tem grandeza alguma. II. Linha é o que tem comprimento sem largura. III. As extremidades da linha são pontos. IV. Linha reta é aquela que está posta igualmente entre as suas extremidades. V. Superfície é o que tem comprimento e largura. VI. As extremidades da superfície são linhas. (Euclides, 1944, p. 4)

POSTULADOS: I. Pede-se, como cousa possível, que se tire de um ponto qualquer para outro qualquer ponto uma linha reta. II. E que uma linha reta determinada se continue em direitura de si mesma, até onde seja necessário. III. E que com qualquer centro e qualquer intervalo se descreva um círculo. IV. Todos os ângulos retos sáo iguais. V. Se duas retas, em um mesmo plano, são cortadas por uma outra reta, e se a soma dos ângulos internos de um lado é menor do que dois retos, então as retas se encontrarão, se prolongadas suficientemente do lado em que a soma dos ângulos é menor do que dois ângulos retos. (Euclides, 1944, p. 7)

Afinal, qual a natureza da Geometria e de seus objetos? Os conteúdos indicados nos Parâmetros Curriculares Nacionais remetem ao en- 
sino de qual Geometria? Existem diferentes geometrias? O que, de fato, representam os objetos da Geometria? Existem, realmente, retas? Planos? Poliedros regulares? Esferas perfeitas? Curvas contínuas?

Toda ciência, inclusive a Matemática, caracteriza-se como uma ocupação/trabalho humano comprometido com a resolução de problemas; uma ocupação que utiliza uma linguagem simbólica e um sistema conceitual que são, ou têm sido, logicamente organizados e socialmente constituídos e compartilhados (Godino; Batanero; Navarro-Pelayo, 1995). Enquanto atividade humana, portanto, a Matemática é uma atividade falível. O matemático Imre Lakatos (1922-1974) mostra essa falibilidade dentro da Matemática quando, por meio de exemplos, apresenta a construção da ciência chamada dura, rigorosa e repleta de certezas, como uma atividade sujeita a erros e a modificaçóes, ou seja, falível (Davis; Hersh, 1985).

Não pensamos com isso que o ensino da Geometria nas escolas, como vem acontecendo, abordando essencialmente a axiomática da Geometria Euclidiana (veja a epígrafe no início dessa seçáo), não possa contribuir para alcançar os objetivos preconizados pelos Parâmetros Curriculares Nacionais para o Ensino Fundamental e para o Ensino Médio. É conhecida a importância de objetivos como proporcionar ao aluno uma melhor compreensão do mundo em que vive, justificando que esse conteúdo lhe permitirá descrever, representar e se localizar no mundo. Justifica-se também o seu ensino pela possibilidade de desenvolver a observação de regularidades, de perceber diferenças e semelhanças e de estabelecer relaçóes com outras áreas de conhecimento, principalmente com as artes (pinturas, desenhos, esculturas, artesanato etc.) (Brasil, 1998, p.72-74). Para o Ensino Médio, dentre outras idéias, afirma-se que:

A Geometria, ostensivamente presente nas formas naturais e construídas, é essencial à descriçáo, à representaçáo, à medida e ao dimensionamento de uma infinidade de objetos e espaços na vida diária e nos sistemas produtivos e de serviços. No ensino médio, trata das formas planas e tridimensionais e suas representaçóes em desenhos, planificaçóes, modelos e objetos do mundo concreto. (Brasil, 2002, p. 123)

No entanto, não há como discordar de que é também esse ensino que vem contribuindo demasiadamente para uma concepção de Matemá- 
tica como ciência perfeita, exata, infalível, reservada aos poucos gênios que conseguem entendê-la. Fato que acaba refletindo nas práticas profissionais dos professores de matemática, que não podem errar, que devem saber tudo, que são rigorosos nas avaliaçóes, que consideram apenas uma resposta como correta etc.

Como mostra a epígrafe do início dessa seção, os conceitos da Geometria Euclidiana são todos ideais: partem de algumas definiçôes, postulados e axiomas, assumidos como verdadeiros e construídos por meio de um raciocínio lógico-dedutivo. Não há mal nisso, posto que foi essa a maneira pela qual Euclides de Alexandria (360 a.C - 295 a.C.) compilou e sistematizou grande parte do conhecimento sobre Geometria da sua época; essa é uma maneira de fazer e pensar Matemática. Não a única.

Porém, náo existem retas e pontos na natureza, tampouco nos objetos construídos pelo homem. Náo existem planos, tal como os concebem as definiçôes da Geometria Euclidiana. Um sólido geométrico não admite ranhuras nem porosidades, linha é o que tem comprimento sem largura (Euclides, 1944). Onde há algo assim na natureza? Nem mesmo um fio de cabelo pode ser chamado de reta, pois tem uma espessura, mesmo que mínima.

Como nos diz Mandelbrot (1998, p. 16):

é ingênuo pretender demonstrar pelo desenho de uma curva que toda função contínua admite uma derivada. Se é verdade que as funçôes com derivada são as mais simples, as mais fáceis de tratar, também é verdade que elas são a exceção, e não a regra. Ou, se preferir a linguagem geométrica, as curvas que não possuem tangente são a regra, enquanto as curvas regulares, como a circunferência, são casos, apesar de interessantes, muito particulares.

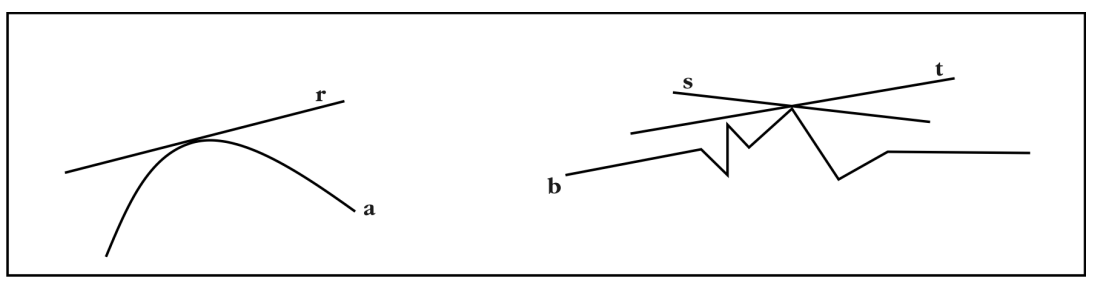

Figura 1 
$\mathrm{Na}$ curva a, a reta $\mathbf{r}$ é sua única tangente no ponto dado. Já na curva $\mathbf{b}$, há uma indecisão sobre a tangente, nem a reta $\mathbf{t}$ nem a reta $\mathbf{s}$ são tangentes a ela.

Ao olhar para as formas da natureza, as árvores, os lagos, os insetos, as formações rochosas, as formaçóes de corais, as formas do corpo humano, os alvéolos pulmonares etc., começamos a lidar com uma aleatoriedade e com um caos que fogem à compreensão proposta pela Geometria Euclidiana. Faz-se necessário, então, uma nova maneira de explicar e compreender,

caracterizada por duas escolhas: a escolha de problemas no seio do caos da natureza, uma vez que descrever todo o caos seria uma ambição sem esperança e sem interesse, e a escolha de ferramentas no seio das matemáticas, pois procurar aplicaçóes das matemáticas pelo simples fato de serem belas acabou sempre por causar dissabores. (Mandelbrot, 1998, p. 18)

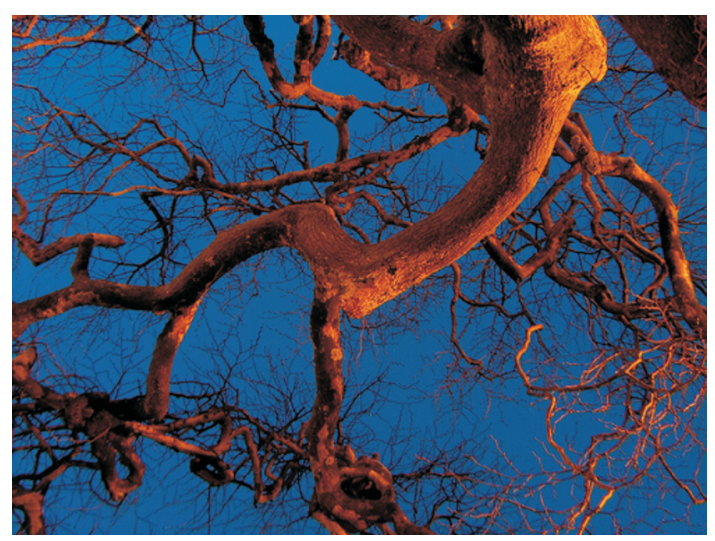

Figura 2 - O caos na natureza

É justamente esse questionamento sobre a Geometria Euclidiana, essa contraposição entre as formas construídas pelo homem e as formas da natureza e suas representaçóes, o fascínio da nova ciência, que está por se apresentar aos alunos.

Com essa discussão concebemos o início da disciplina intitulada Geometrias e Artes, no qual o papel da observação de regularidades, padrões e, principalmente, estruturas caóticas, pôde ser potencializado, pois houve a possibilidade de realizar aulas sob uma árvore, no pátio da escola, ou em lugares onde o contraste entre as formas da natureza e as formas 
construídas pelo homem fosse ostensivo. Houve um momento para estimular a criatividade dos alunos, chamados a contemplar e representar o que viam, utilizando desenhos geométricos e recordando, assim, figuras geométricas planas e espaciais e suas propriedades. Uma atividade semelhante, ao menos na questão da observação, à desenvolvida pelo artista Paul Cézanne (1839-1906) em sua pintura: observar a natureza e os objetos construídos pelo homem e tentar reconstruir o espaço pictórico segundo a "geometria que estava nas coisas mesmas" (Gullar, 1985, p. 17). A educação do olhar foi, na verdade, uma intenção que permeou toda a concepção e realização das aulas.

Com isso, concluímos que os objetos construídos pelo homem (casas, escolas, carros, cadeiras, portas, janelas etc.), em sua maioria, permitem uma representação mais simples, como um triângulo justaposto a um retângulo para representar a vista frontal de uma casa ou um cone com uma esfera em sua base para representar um sorvete. Já com a natureza, precisamos improvisar mais: 'torcer' um quadrado para representar a visão frontal do caule de uma árvore, usar cilindros pequenos unidos um ao outro para dar a idéia dos galhos, pensar em buracos nos cilindros, quebrar cubos e pirâmides, tomar pequenos pedaços de um segmento de reta, ou seja, faz-se necessário 'quebrar' os objetos geométricos, reinventar a Geometria Euclidiana.

Essa questão leva à percepção de que uma lente de aumento nos faria ver uma série de sinuosidades e porosidades - mesmo em objetos construídos pelo homem - que aparentemente os objetos não apresentam. Essas estruturas caóticas são exemplos intuitivos do que Benoit Mandelbrot (matemático polonês nascido em 1924) denominou fractais; termo oriundo do adjetivo latino fractus, relativo ao verbo frangere, que significa quebrar, criar fragmentos irregulares, fragmentar. Ou seja, entre "o domínio do caos desregulado e a ordem excessiva de Euclides existe agora a nova zona da ordem fractal" (Mandelbrot, 1998, p. 18).

A figura 03 é um exemplo de curva sem tangente, construída pelo matemático polonês Helge Von Koch (1870-1924), sobre a qual podemos imaginar a representação de uma linha costeira, litorânea. Quanto mais nos aproximamos da costa, mais baías aparecem, em maior quantidade são as sinuosidades, as reentrâncias.

Sobre uma folha de papel poderíamos dizer simplesmente que representa um plano ou um retângulo. Porém, observando com mais detalhes e 
mais de perto, podemos ter uma compreensão diferente desse objeto. Veja o objeto fractal intitulado "Tapete de Sierpinski" (figura 4) e repare o que acontece no decorrer do processo iterativo (a, b, c, d, e).

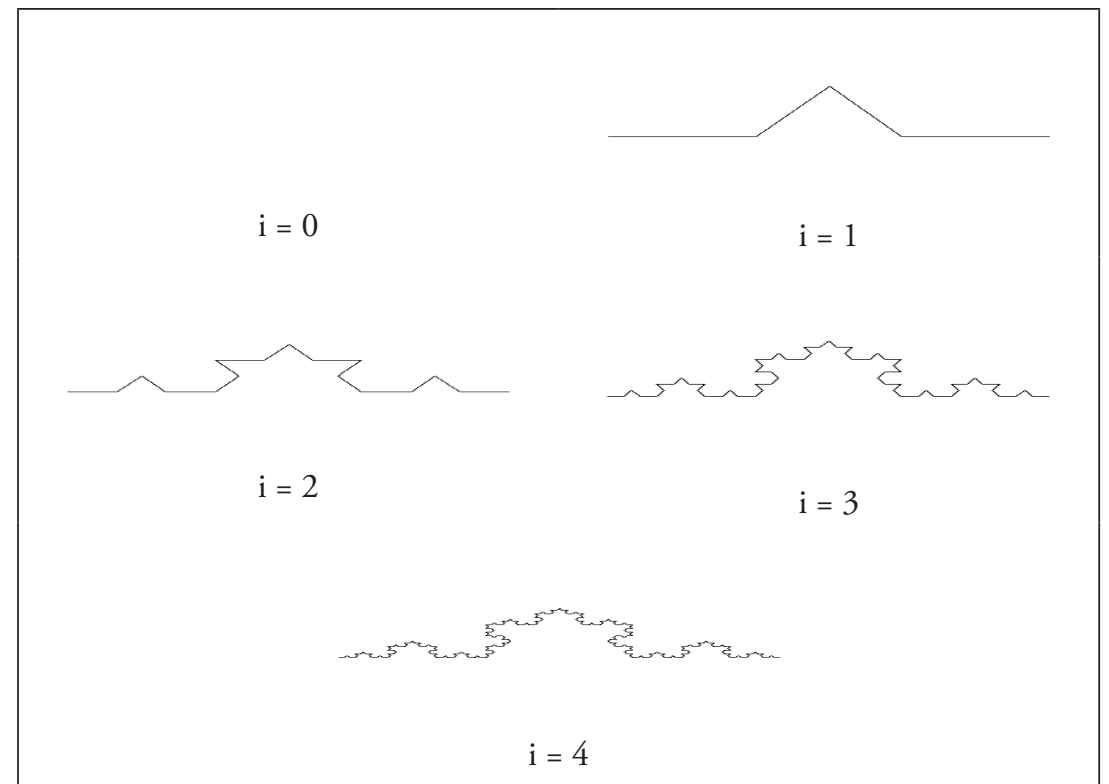

Figura 3 - Curva de Koch

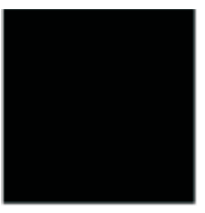

a

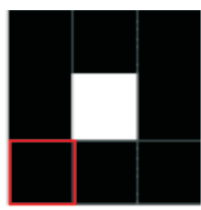

b

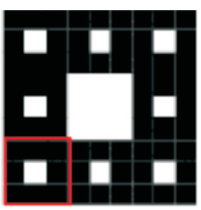

C

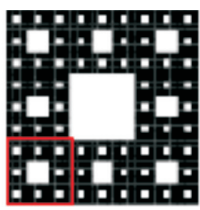

d

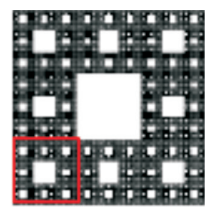

e

Figura 4 - Tapete de Sierpinski

Uma espécie de pintura conformada em 'cubinhos', assim como disse Louis Vauxcelles (1870-1943), crítico de arte, quando observou pela primeira vez algumas pinturas de Georges Braque (1882-1963): "Ele (Braque) despreza as formas, reduz tudo, sítios e figuras e casas, a esquemas geométricos, a cubos" (Vauxcelles apud Gullar, 1985, p. 5). Na verdade, essa 'cubificação' logo fora abandonada pelos pintores 
cubistas, que partiram para uma planificação dos objetos, o que fez desaparecer dos seus quadros não só a terceira dimensão, mas também os cubos (ver figura 5).

Chegamos a um ponto crítico do que estamos estudando. Afinal, os objetos euclidianos têm dimensão zero, como o ponto que não tem largura nem comprimento; dimensão 1 , como a reta; dimensão 2 , como o plano; ou dimensão 3, como um cubo, que tem comprimento, largura e altura. No entanto, o que podemos dizer dessas cinco figuras apresentadas no texto? $\mathrm{Na}$ figura 4 , à medida que o procedimento iterativo (na seqüência a, b, c, d) se desenvolve, a figura torna-se um plano com dimensão 2? Ou será que esse plano ficará de tal maneira repleto de pequenos furos que não poderemos afirmar certezas sobre sua dimensão? E quanto ao quadro de Pablo de Picasso, qual a dimensão desse desenho? Bidimensional?

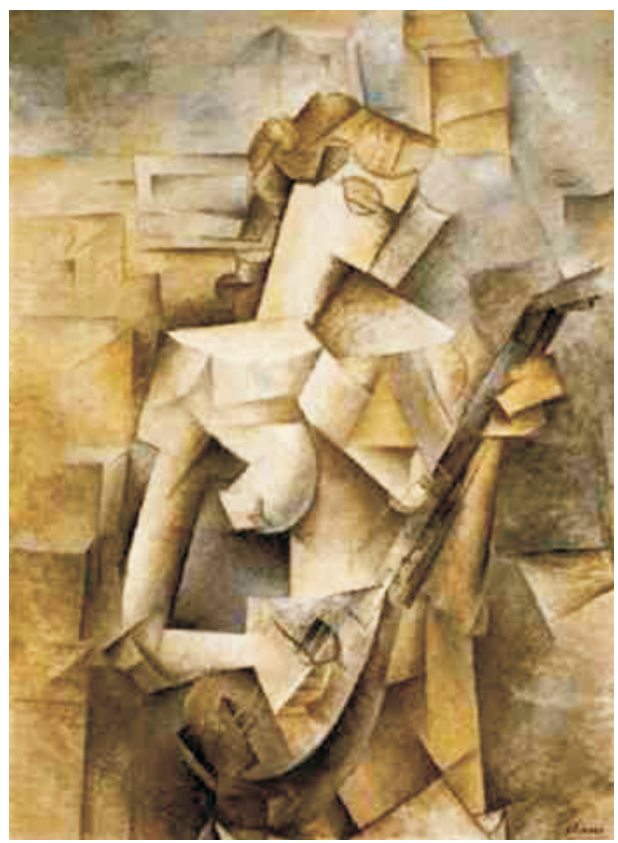

Figura 5 - Menina com Bandolim, Pablo Picasso (Museu de Arte Moderna, Nova York) 
As figuras sugerem um questionamento sobre a idéia de dimensão. Tomando um exemplo de uma pequena bola de algodão, quando observada a certa distância, pode-se dizer que é um ponto. Mas, se houvesse uma pulga sobre a bola de algodão, se teria a impressão de um objeto poroso, talvez de dimensão 3. No tapete de Sierpinski, é como se olhássemos cada vez mais perto, conforme se passa de uma iteração a outra, até chegar a uma visão microscópica. Poderia a dimensão de um mesmo objeto variar de acordo com a escala? Esse questionamento é uma das idéias responsáveis pelo nascimento de uma nova geometria, a Geometria Fractal (Mandelbrot, 1998).

No caso da pintura de Pablo Picasso, de fato, enquanto pintura em uma tela, sempre diremos que é bidimensional. No entanto, embora a perspectiva dê a clara idéia de uma menina ocupando um espaço tridimensional, ficamos perplexos ao observar a inventividade do artista. A pintura cubista deixou de ser meramente figurativa, afastando-se da fotografia, e a terceira dimensão parece um tanto 'planificada', como se o pintor quisesse mostrar outras faces do objeto: "Os cubistas não representavam os vários lados do objeto para nos dar uma visão mais completa ou mais verdadeira do real: eles se valiam dessa possibilidade para libertá-lo, para esvaziá-lo de sua condição natural” (Gullar, 1985, p. 71)

Interpretações desse conflito em que a contraposição entre o cubismo e a figuração é acentuada levaram os críticos a recorrer às noçóes matemáticas de espaço. Guillaume Apollinaire (1880-1918), por exemplo, refere-se à quarta dimensão (as três dimensóes mais o tempo) para interpretar o cubismo. Albert Gleizes (1881-1953) e Jean Metzinger (1883-1956), em uma necessidade de racionalizar essa nova pintura, afirmaram que, geometricamente, o espaço cubista apenas poderia ser estudado dentro da geometria não-euclidiana, "negam em seguida que possa a perspectiva 'evocar a idéia de profundidade" (Gullar, 1985, p. 72).

O quinto postulado de Euclides, enunciado no início dessa seção, é a chave para entender o surgimento das geometrias não-euclidianas. Costumou-se chamá-lo de postulado das paralelas e sua formulação acabou sendo substituída por uma equivalente: "Sejam dados, em um plano, uma reta $\mathrm{L}$ e um ponto $\mathrm{P}$ que não está em $\mathrm{L}$. Então existe uma e só uma paralela a L passando por P” (Davis; Hersh, 1985, p. 252). Um postulado significa que o enunciado trata de uma verdade evidente que dispensa demonstrações, no entanto, os matemáticos não se convenceram da verdade 
deste postulado tão facilmente como se convenceram dos outros quatro. As tentativas de fazer uma demonstração deduzindo-o dos quatro primeiros postulados fracassaram até que dois matemáticos, Girolamo Saccheri (1667-1733) e Hohann Lambert (1728-1777), acabaram por encontrar contradiçóes nesse postulado. Assim, à maneira de Euclides, segundo um jogo dedutivo e resultado do trabalho de muitos matemáticos, outras geometrias nasceram: as geometrias não-euclidianas.

Para uma idéia intuitiva, imaginemos um triângulo gigante com um vértice na América do Sul, outro no Pólo Norte e o terceiro em algum lugar da Europa. A soma de seus ângulos internos será $180^{\circ}$ ? Nesse caso, os lados do triângulo seriam algum tipo de 'reta curva' como um meridiano ou a linha do equador, por exemplo. Eles seriam geodésicos, que são as 'retas' de algumas geometrias não-euclidianas como a esférica e a hiperbólica (veja figura 6).

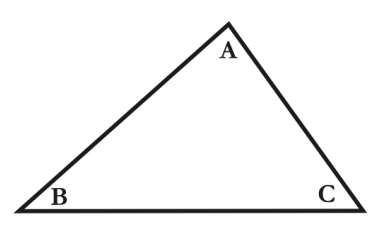

Geometria Euclidiana $A+B+C=180^{\circ}$

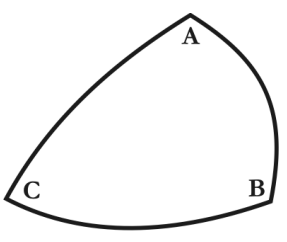

Geometria Esférica $A+B+C>180^{\circ}$

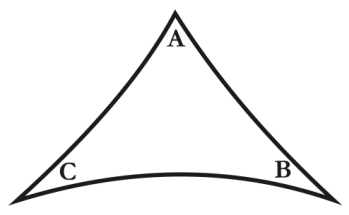

Geometria Hiperbólica $A+B+C<180^{\circ}$

Figura 6

As interpretações matemáticas do cubismo não o concebiam como uma nova linguagem, uma revolução plástica radical, por isso Gullar (1985) afirma que os críticos assustaram-se ao perceberem "uma transformação dos hábitos de ver”. Isso fez surgir essa tentativa de racionalizar, de dar explicaçóes acadêmicas - o que foi importante - porém, o cubismo ia além: "Um dos efeitos comuns das obras de arte é revelar novos aspectos do mundo exterior e nos fazer ver segundo as relaçóes que essas obras inauguram" (Gullar, 1985, p. 72).

Interessante notar como o processo criativo da arte pictórica passou de um olhar contemplativo e reprodutor da natureza para, progressivamente, despregar-se dessa idéia de imitação a caminho de um processo mais abstrato. A arte cubista está longe de ser figurativa, ou 
simplesmente mimese, mas também está longe de se desvincular totalmente das figuras reais, pois é a partir delas que os cubistas produziam a sua interpretação. A menina com o bandolim não nos parece somente uma menina, ela nos dá a possibilidade de lhe atribuir diferentes significados.

A busca de uma arte que não apenas represente, oferecendo-nos a possibilidade de apenas um significado, que é aquilo que vemos, dá lugar a uma arte que permite abrir a possibilidade de significados, transformando-se em enigma ou equação que precisa ser desenvolvida mentalmente. Muitas vezes ela se apresenta com mais de uma incógnita e a solução não está no mundo visível. (Luz, 2002, s/p)

Deve-se ao pintor russo Malevitch (1878-1935) e ao holandês Mondrian (1872-1944) o rompimento radical com a arte do passado, pois eles náo viram no cubismo simplesmente uma seqüência lógica dos movimentos artísticos anteriores (pintura impressionista, renascentista etc.), mas perceberam uma nova linguagem, uma nova maneira de olhar. Esses artistas esgotaram "implacavelmente as últimas alusões ao mundo natural que restavam na linguagem da pintura, e redescobriram, sob a pasta pictórica que os séculos acumularam sobre a superfície da tela, a tela em branco" (Gullar, 1985, p. 137). Eles extraíram as formas essenciais que estavam subjacentes ao cubismo, despojando-se de qualquer alusão à natureza. Surgem, então, os movimentos como o suprematismo, o náo-objetivismo, o construtivismo, o neoplasticismo. Assim, é a pintura abstrata que toma força, "apenas a tela, ou o muro, enfim, o suporte que pode apreender o real, ou seja, o pensamento do artista" (Luz, 2002, s/p), e tem também em Wassily Kandinsky (1866-1944) um grande nome, tido como fundador da pintura abstrata (Ricart, 2007).

Embora possa parecer uma pintura feita ao acaso (figura 7), tornando-se caótica, Mondrian, assim como Kandinsky, buscava a precisão, o equilíbrio, tendo a técnica como ferramenta para estabelecer uma "plástica precisa", uma "plástica do puro equilíbrio", inconcebível sem a dualidade (Mondrian apud Luz, 2002, s/p). É uma tentativa de domar o acaso, estabelecer uma ordem no caos, colocar no quadro a relação equilibrada entre intuição e técnica, entre individual e universal. 


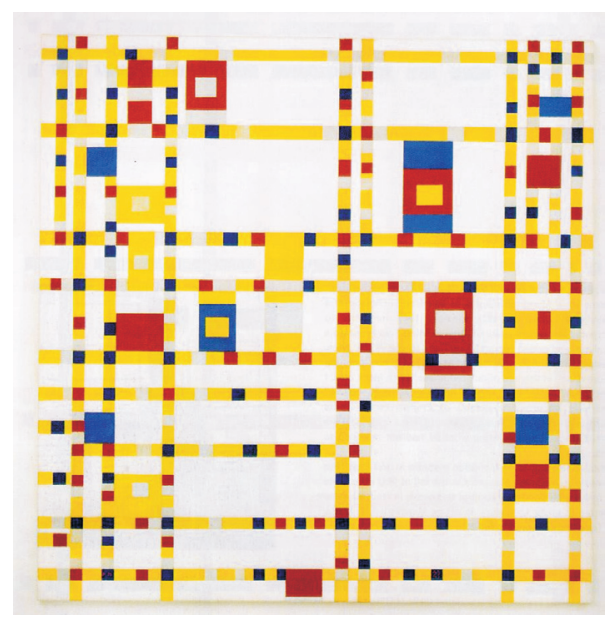

Figura 7 - Piet Mondrian (Broadway BoogieWoogie (1942/3) Museu de arte moderna, Nova York.

$\mathrm{Na}$ física, a teoria da relatividade de Albert Einstein (1879-1955) permite estabelecer a reação em cadeia que ocorre depois que o primeiro átomo se desintegra, mas não pode antecipar qual deles será o primeiro. É também o acaso desafiando a ciência, assim como a pintura (Luz, 2002).

A Geometria Fractal aparece aqui outra vez, afinal, ela parte do seio caótico da natureza para construir sua interpretação. Como em um ciclo, retomamos a pintura que, embora relacionada com o abstracionismo de Kandinsky e o neoplasticismo de Mondrian, não é necessariamente uma seqüência dessas correntes. Retomamos, porque alguns artistas acabaram usando o caos como ponto de partida para suas obras. Jackson Pollock (1912-1956) desenvolveu uma técnica de pintura na qual respingava a tinta sobre suas imensas telas, deixando os pingos escorrerem imprevisivelmente, formando traços harmoniosos entrelaçados na superfície. Esse artista estendia sua tela no chão, invadindo o quadro para pintar, usando bastóes, colheres e não mais o pincel (Pollock, 2000), resultando uma arte que é quase uma ode ao caos, à aleatoriedade, mas que não deixa de ser harmoniosa e bela, eternizando a pintura, "no plano da tela, quando a mesma procura um outro espaço, o da contemplação do espectador" (Luz, 2002, s/p). 
O matemático Kurt Gödel (1906-1978) afirma haver uma incompletude na racionalidade da teoria matemática ao verificar que em qualquer sistema adequado à teoria dos números existirá um axioma completamente independente a ela, ou seja, existem algumas afirmaçóes dentro da teoria que não poderão ser provadas por essa mesma teoria: são as proposiçóes matemáticas indecidíveis (Davis; Hersh, 1985). Estudos sobre esse fato deram ao matemático Gregory John Chaitin (argentino, nascido em 1947) as bases para estabelecer a Teoria da Complexidade Computacional, que trata da probabilidade de mau funcionamento aleatório de um programa. Assim, a matemática revela-se não somente incompleta, mas também aleatória (Lemos et al., 2007).

Tanto as artes como a matemática e as ciências mostram-se, em certo momento, desprovidas de certezas, questionando-se, repletas de imprecisóes e aleatoriedade. A Teoria do Caos, surgida na década de 60 , vem reforçar essas idéias de aleatoriedade e de instabilidade, mas ainda sem perder de vista a tentativa de estabelecer e observar ordens subjacentes ao caos. $\mathrm{O}$ matemático Edward Norton Lorenz (1917-2008), do Instituto Tecnológico de Massachusetts (MIT), com a publicação do artigo "Previsibilidade: o bater de asas de uma borboleta no Brasil pode desencadear um tornado no Texas?", cria um termo muito famoso atualmente, Efeito Borboleta, que é "a propriedade de um fenômeno muito pequeno dar origem a outro muito grande" (Lemos et al., 2007). Incrivelmente, a resposta à pergunta de Lorenz é sim.

Enquanto Heisenberg e Niels Bohr estavam estudando com Einstein a indeterminação, o acaso e a relatividade, várias coisas estavam ocorrendo na pintura, na literatura e no cinema nascente. A arte de vanguarda estava surgindo, colocando tudo em dúvida, mudando a perspectiva, a figuraçáo, procurando o que seria uma espécie de 'antimatéria' e 'anti-arte' (Sant'Anna, 2006, p. 219).

Por fim, é sempre o homem confrontando seu olhar com os objetos e fenômenos naturais, tentando explicar, compreender, interpretar, ressaltar o belo. $\mathrm{O}$ belo na arte, o belo na Matemática, a incerteza, a aleatoriedade, a ordem e o caos instigando o homem a produzir, do ponto de vista científico, artístico e, agora, neste texto, pedagógico, procurando ordens no caos da interdisciplinaridade entre as artes, as geometrias, a filosofia e a física. 


\section{Revista Solta a Voz, v. 19, n. 2}

\section{OUTRAS POSSIBILIDADES DIRECIONADAS AO ENSINO DA MATEMÁTICA}

Essas idéias apresentadas apareceram durante as aulas da disciplina Geometrias e Artes de três maneiras: seminários apresentados pelos alunos, resolução de problemas e aulas expositivas e intervençóes feitas pelo professor.

Os alunos apresentaram seminários sobre algumas fases da arte contemporânea (o cubismo e o abstracionismo, principalmente) e sobre alguns matemáticos precursores de idéias fractais, como George Cantor (1845-1918) e Waclaw Sierpinski (1882-1969), momentos nos quais o professor pôde intervir, estabelecendo relaçóes, apresentando as idéias gerais da Geometria Fractal e das geometrias não-euclidianas, conforme aparecem neste texto.

Para mostrar as diferenças entre a pintura cubista e a abstracionista utilizamos trechos do filme "Modigliani - Paixão pela Vida", sobre um pintor contemporâneo a Pablo Picasso, e o filme "Pollock", sobre o pintor expressionista abstrato já citado anteriormente.

Cabe ressaltar que os alunos, atores ativos no processo de ensino e aprendizagem, tentaram eles mesmos estabelecer algumas conexóes, com destaque para a pintura abstrata e a Geometria Euclidiana. Durante os seminários eles evidenciaram o aspecto técnico da pintura abstrata, mostrando como os artistas utilizavam as idéias de retas, linhas e ângulos retos para dividir o quadro e estabelecer um equilíbrio, harmonizando-o para que o público pudesse contemplar o puro, o belo. Ainda, o uso de quadrados, círculos e outras figuras geométricas apareceram para eles como evidências matemáticas na pintura.

A resolução de problemas foi utilizada na intenção de fazer os alunos observarem padróes geométricos em objetos fractais. No tapete de Sierpinski, por exemplo, um dos problemas colocados foi o seguinte: se em cada iteração são retirados alguns quadrados do tapete, esburacando-o, conforme mostra a figura 4, qual é a área do tapete depois de 8 iteraçóes? E depois de $\mathbf{n}$ iteraçóes?

Como exemplo, suponha que a figura inicial do tapete de Sierpinski seja um quadrado de área 1. Após a primeira iteração (iteração a na figura 4), retira-se $1 / 9$ da área do tapete, restando $\frac{8}{9}$. Após a segunda iteração, retira-se $8 / 81$ da área restante na primeira iteração. Restam, portanto: $\frac{8}{9}-\frac{8}{81}=\frac{64}{81}$ 
Colocando numa tabela, temos o seguinte:

Tabela 1 - O processo iterativo do Tapete de Sierpinski

\begin{tabular}{c|c|c}
\hline ITERAÇÃO & $\begin{array}{c}\text { ÁREA } \\
\text { RETIRADA }\end{array}$ & $\begin{array}{c}\text { ÁREA } \\
\text { RESTANTE }\end{array}$ \\
\hline 0 & 0 & $\frac{8}{9}$ \\
\hline 1 & $\frac{1}{9}$ & $\frac{8^{2}}{9^{2}}=\frac{64}{81}$ \\
\hline 3 & $\frac{8}{9^{2}}=\frac{8}{81}$ & $\frac{8^{3}}{9^{3}}=\frac{512}{729}$ \\
\hline 8 & $\frac{8^{2}}{9^{3}}=\frac{64}{729}$ & $\frac{8^{8}}{9^{8}}=\frac{16777216}{43046721}$ \\
\hline$\vdots$ & $\frac{8^{7}}{9^{8}}=\frac{2097152}{43046721}$ & $\vdots$ \\
\hline $\mathbf{n}$ & $\frac{8^{n-1}}{9^{n}}$ & $\frac{8^{n}}{9^{n}}$ \\
\hline
\end{tabular}

Entre outros problemas, com outros fractais não apresentados aqui, esse tipo de atividade mostrou-se bastante produtiva na medida em que os alunos perceberam os conceitos de progressão geométrica e seqüências matemáticas como importantes para resolvê-los.

Esse tipo de problema, juntamente com as idéias da pintura cubista e do expressionismo abstrato, serviu como ponto de partida para apresentar aos alunos, durante as aulas expositivas, as idéias matemáticas de dimensão. Em figuras fractais, a dimensão é calculada de acordo com seu fator de reduçáo e, para isso, é necessário utilizar logaritmos como ferramenta. A dimensão de um fractal pode ser obtida pela seguinte equação (Gouvea, 2005):

$$
N=\left(\frac{C}{m}\right)^{-D} \text {, onde } \mathbf{D} \text { é a dimensão fractal procurada, } \mathbf{m} \text { é fator de }
$$

contração, ou seja, o número de partes em que o segmento foi dividido, C 
é o comprimento do segmento estudado e $\mathbf{N}$ é o número total de contrações. Aplicando logaritmo a ambos os membros da equação, temos:

$$
D=\frac{-\log N}{\log \left(\frac{C}{m}\right)}
$$

No fractal chamado curva de Koch (figura 3), supondo o segmento inicial de tamanho 1 (em $\mathrm{i}=0$ ), percebe-se que ele foi dividido em 3 segmentos iguais, sendo substituído, em $\mathrm{i}=1$, por 4 segmentos congruentes. Assim, o número total de contrações é $N=4$ e o fator de contração é $m=1 / 3$. Logo, $D=\frac{-\log 4}{\log \left(\frac{1}{3}\right)}=\frac{-\log 4}{\log 1-\log 3}=\frac{-\log 4}{0-\log 3} \cong 1,262$.

Por a curva de Koch ser curva facilmente se concluiria que não é um plano, com dimensão 2. No entanto, como curva, como algo no espaço, vê-se pela sua dimensão que se trata de uma curva no espaço que não pode ser situada no plano.

Um contraponto em relação à idéia de dimensão é a pintura de Maurits Cornelis Escher (1898-1972), que apareceu em alguns momentos das aulas para que pudéssemos contemplar suas contradiçóes em relação à dimensão. Ainda, foi possível reproduzir com os alunos algumas de suas técnicas, utilizando alguns conceitos e procedimentos de Desenho Geométrico.

\section{UMA PALAVRA FINAL}

Durante todo esse trabalho, desde a concepção da disciplina até a sua realização, um questionamento nos perseguiu: trata-se de um trabalho interdisciplinar? Ao propor uma disciplina para a matriz curricular do núcleo flexível do Ensino Médio, cumprindo uma das nossas atribuiçóes profissionais, acabei por adentrar em um terreno nebuloso até mesmo no nome: propor uma 'disciplina interdisciplinar'.

Comecei a desenvolver o trabalho com a intenção de estabelecer um caminho, preocupado com a educação do olhar, no meio da qual pudesse inserir interessantes idéias matemáticas, quase que apresentando motivos para ensinar matemática. A literatura classifica como "interdisciplinaridade escolar" aquela que tem por finalidade a difusão do conhecimento, o favorecimento 
da integração de aprendizagens e conhecimentos, a formação de atores sociais (Lenoir, 1998). Desse modo, embora apareça entre artes e matemática alguma ligação epistemológica, concernente às teorias do caos e a pintura abstrata, não pretendi hierarquizar conhecimentos, preencher lacunas das disciplinas científicas ou mesmo criar uma. Tâo somente tentei estabelecer ligaçóes entre teoria e prática, trabalhando com "as condições mais apropriadas para suscitar e sustentar o desenvolvimento dos processos integradores e a apropriação dos conhecimentos como produtos cognitivos com os alunos" (idem, p. 53).

Concernente ao trabalho dos alunos, surpreendeu-me o fato do assunto ter despertado interesse, mesmo sendo, algumas vezes, tão contemplativo e filosófico. Embora essas características não sejam entediantes, a surpresa deveu-se ao fato de os alunos aceitarem esse caminho proposto pelo professor de matemática, já que tradicionalmente espera-se dele uma série de cálculos, contas, expressóes, demonstrações etc. Além de aceitarem, os alunos mostraram-se capazes de fazer suas próprias conexóes, assumindo uma resposta clara no contrato didático: não se trata de ensinar e aprender matemática somente, mas também de assumir explicitamente atitudes questionadoras: "Isso cai no vestibular?".

Enfim, longe de responder às diversas angústias presentes no trabalho do professor diante de uma proposta pedagógica, diante de um currículo, diante de uma turma de alunos, frente à insegurança que toda viagem ao novo causa, deixo ao leitor um caminho traçado, não para ser imitado, mas para ser refeito, repensado, desvendando outras possibilidades e novos olhares.

\section{REFERÊNCIAS}

BRASIL. Secretaria da Educação Fundamental. Parâmetros Curriculares Nacionais: terceiro e quarto ciclos do Ensino Fundamental - introduçáo aos Parâmetros Curriculares Nacionais. Brasília: MEC/SEF, 1998.

BRASIL. Secretaria da Educação Média e Tecnológica. Parâmetros Curriculares Nacionais: ensino médio. Brasília: MEC; SEMETEC, 2002.

DAVIS, P. J.; HERSH, R. A experiência matemática. Rio de Janeiro: Francisco Alves, 1985.

EUCLIDES. Elementos de geometria. Trad. de Frederico Commandino. São Paulo: Ediçôes Cultura, 1944. Disponível em: <http://www.dominiopublico.org.br>. Acesso em: 24 jun. 2007. 


\section{Revista Solta a Voz, v. 19, n. 2}

GODINO, J. D.; BATANERO, C.; NAVARRO-PELAYO, V. Epistemology and mathematics instruccion: implications for curricular development. In: International conference on systematic cooperation between theory and practice in Mathematics education, 5, 1994, Grado, Italy. Proccedings of the... Pavia: ISDAF, 1994. p. 9-18.

GOUVEA, F. R. Ensino-aprendizagem de geometria: um estudo de fractais geométricos que inclui caleidoscópio e softwares de geometria dinâmica. 2005. Dissertação (Mestrado em Educação Matemática) - Universidade Estadual Paulista, Rio Claro, São Paulo, 2005.

GULLAR, F. Etapas da arte contemporânea: do cubismo ao neoconcretismo. São Paulo: Nobel, 1985.

LEMOS, R. T. S. et al. Tecnologia e complexidade. Ciências \& Cognição, v. 11, ano 4, 2007. Disponível em <http://www.cienciasecognicao.org/artigos/v11/337172.html>. Acesso em: 10 jan. 2008.

LENOIR, Y. Didática e interdisciplinaridade: uma complementaridade necessária e incontornável. In: FAZENDA, I. (Org.). Didática e interdisciplinaridade. Campinas: Papirus, 1998.

LUZ, A. A. da. Artes visuais e matemática. Disponível em <http://www. tvebrasil.com.br/SALTO/boletins2002/ame/ametxt2.htm>. Acesso em: 10 jan. 2008.

MANDELBROT, B. Objetos fractais: forma, acaso e dimensão. Lisboa: Gradiva, 1998.

MODIGLIANI: paixão pela vida. Direção Mick Davis. Estados Unidos, 2004. 1 viodeocassete (128 min), VHS, Ntsc, son., color., Legendado. Port.

POLLOCK. Direção: Ed Haris. Produção Fred Berner, Ed Harris, Jon Kilik. Estados Unidos, 2000. 1 DVD (117 min.) DVD, son., color., Legendado. Port.

RICART, J. (Coord.). Wassily Kandinsky. Barcelona: Sol 90, 2007.

SANT'ANNA, A. R. de. O lado poético da ciência. (Entrevista concedida a Carla Almeida). História, Ciências, Saúde - Manguinhos, v. 13 (suplemento), p. 213-22, 2006. 